Original Research Paper

\title{
Shore Line Mathematical Modelling and Integrated Groundwater Potentiality Study in the Northern Coast Mediterranean Sea, Egypt
}

\author{
${ }^{1,2}$ Rasha El Gohary \\ ${ }^{1}$ Central Laboratory for Environmental Quality Monitoring, National Water Research Center, NWRC, MWRI, Cairo, Egypt \\ ${ }^{2}$ El-Gezera High Institute for Engineering and Technology, Ministry of Higher Education, Cairo, Egypt
}

\author{
Article history \\ Received: 18-02-2020 \\ Revised: 14-04-2020 \\ Accepted: 06-05-2020 \\ Corresponding Author: \\ Rasha El Gohary \\ Central Laboratory for \\ Environmental Quality \\ Monitoring, National Water \\ Research Center, NWRC, \\ MWRI, Cairo, Egypt \\ Email: rm.elgohary@yahoo.com \\ drrasha.elgohary@gi.edu.eg
}

\begin{abstract}
The purpose of this research is to determine surface and subsurface features in the proposed sites. Meanwhile accessibility and availability of water resources. It will have carried out a comprehensive investigations related to topography, geology, hydrology and geophysics. Water samples were collected from the study area and its surroundings to be subjected to different analysis procedures for quality and quantity. The results of the hydrologic analysis showed that all rainfall amounts are infiltrated to the soil and there is no runoff flood water to affect the study area. Consequently, it's concluded that the flood has no harm effect on any of the study area buildings. Based on the geophysical and hydrogeological results, it is strongly recommended drilling three productive wells to a depth of $\pm 50 \mathrm{~m}$ at the location of Vertical Electrical Sounding VESes 5 and 7 to produce water from the coral reefs limestone layer where its high fracture density and lower salinity. For future sustainable development plans, it is also possible to drill any number of productive wells in the southern part of the area to avoid the higher degree of sea water intrusion. In this case, the distance between wells must be not less than $120 \mathrm{~m}$. It is conducting a numerical simulation to the coast of the study area in order to inspect the effects of implementing these structures. For that reason, a topographical and a bathymetrical survey were carried to the area in order to simulate the area numerically. The shoreline stabilization was simulated using 20 different orientations to the intake and outlet structures. Based on the mathematical modeling results, it was noticed that the shoreline is naturally stable as it is a smooth East-West shoreline with no undulations and the amount of sediment transport is trivial.
\end{abstract}

Keywords: Mathematical Modeling, Shore Line Stabilization, Hydrology, Water Resources

\section{Introduction}

The Northern Egyptian coastal region is a highly attractive area for tourism development. The study area is a very promising area for tourism activity (Abd-Alrahman and Shanab, 2012). The coastline of the area is a rocky beach, where only $350 \mathrm{~m}$ is considered to be a sandy segment with a clear crystal water. In arid regions like Egypt, the deterioration of fresh water resources in coastal regions threatens the sustainable economic development (Mustafa et al., 2016; Aya et al., 2017; Mustafa et al., 2016; Hussein and Barseem, 2018; Yahia et al., 2017; Abd-Alrahman and Shanab, 2012). Northern Egyptian coast is suffering from a lack of fresh surface water and insufficient rainfall. Groundwater is the only water resource for drinking and development. The Egyptian government has put a strategy to develop the coastal areas in order to solve the problems of water deficiency.

Groundwater investigations are of great importance to face the expecting huge demand on water. This will achieve the Egyptian Sustainable Development Strategy: Egypt Vision 2030 SDS and environmental urban development that target a balanced spatial development management of land and natural resources that improve population welfare. (CAPMS, 2017; UN MDG, 2013; MOP, 2015). The study area lies in the northern Egyptian coast between $28^{\circ} 30^{-}$and $29^{\circ} 00^{-}$East latitude and $30^{\circ} 50^{-}$and $31^{\circ} 10^{-}$North latitude. 


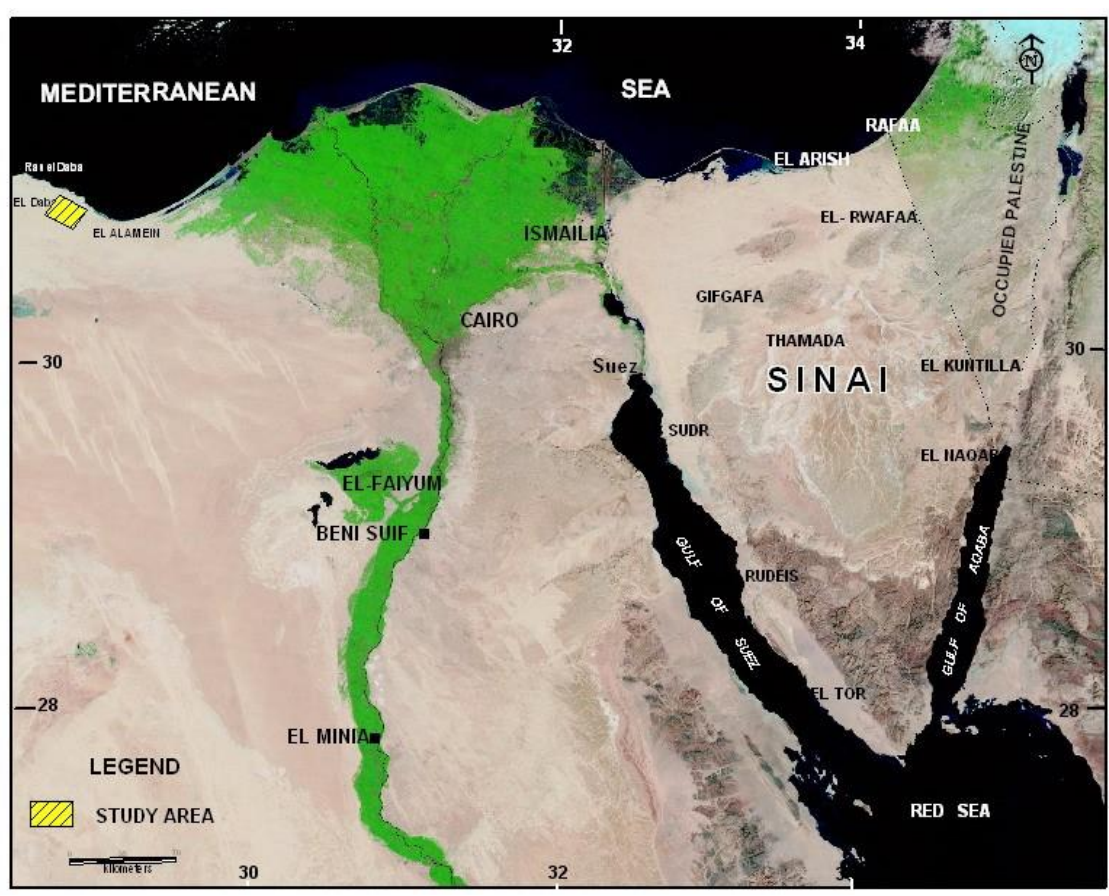

Fig. 1: General location of the study area

It is bounded from the north by the Mediterranean Sea, Wadi El Natroun from the south and western desert from east and west as shown in Fig. 1. An integrated study was investigated in order to govern the suitability of the ground water for touristic development projects. Shore line was studied for stabilization and simulation.

\section{Methodologies, Results and Discussions}

\section{Objectives and Scope of the Study}

The purpose of this study is to determine a water supply in the surrounding area. It will have carried out a comprehensive investigation related to topography, geology, hydrology and geophysics. Also the available water samples were collected from the study area and its surroundings to be subjected to different analysis procedures for quality and quantity. Shore line mathematical modelling and numerical simulation of the study area is carried out for the study area which is located $139 \mathrm{~km}$ to the west of Alexandria and about 7 $\mathrm{km}$ to the west of Sidi Abdel-Rahman City. It is conducting a numerical simulation to the coast of the study area in order to inspect the effects of implementing the structures. For that reason, a topographical and a bathymetrical survey were carried to the area in order to simulate the area numerically.

\section{Integrated Groundwater Potentiality Study}

Egypt is an arid country and the ground water is the main sources of water in this area. Most of the ground water in the area surrounding is a saline water due sea water recharge (WRRI, MWRI, 2013). An integrated study was done in order to explore this area and water resources quality and quantity for Touristic development. Also, time of flash floods is also very important to determine the flash flood mitigation plans. It will have carried out a comprehensive investigation related to topography, geology, hydrology and geophysics. Also the available water samples were collected from the study area.

\section{Geological Investigation}

Figure 2 shows the geological map of the study area. The geological succession of the rock units classified from top to bottom as follows.

\section{Quaternary Deposits}

a. Sand, gravel and recent coastal deposits: These deposits cover a large area from the coastal region, it is extending from east to west with thickness ranging from 40 to $50 \mathrm{~m}$ according to the nature of deposition

b. Limestone and sand deposits: These deposits composed of sand intercalated with limestone, marl and marine coastal sediments and defined as Alexandria Formation, it occurs in the north western part in a small part of the study area

c. Gravel: This gravel was found as a result of erosion and distributed as a narrow ribbon along the coastal region

d. Sabkha deposits: These deposits composed mainly of silt, clay, evaporates and occur along the coastal line and affected by high and low tides and also by evaporation 


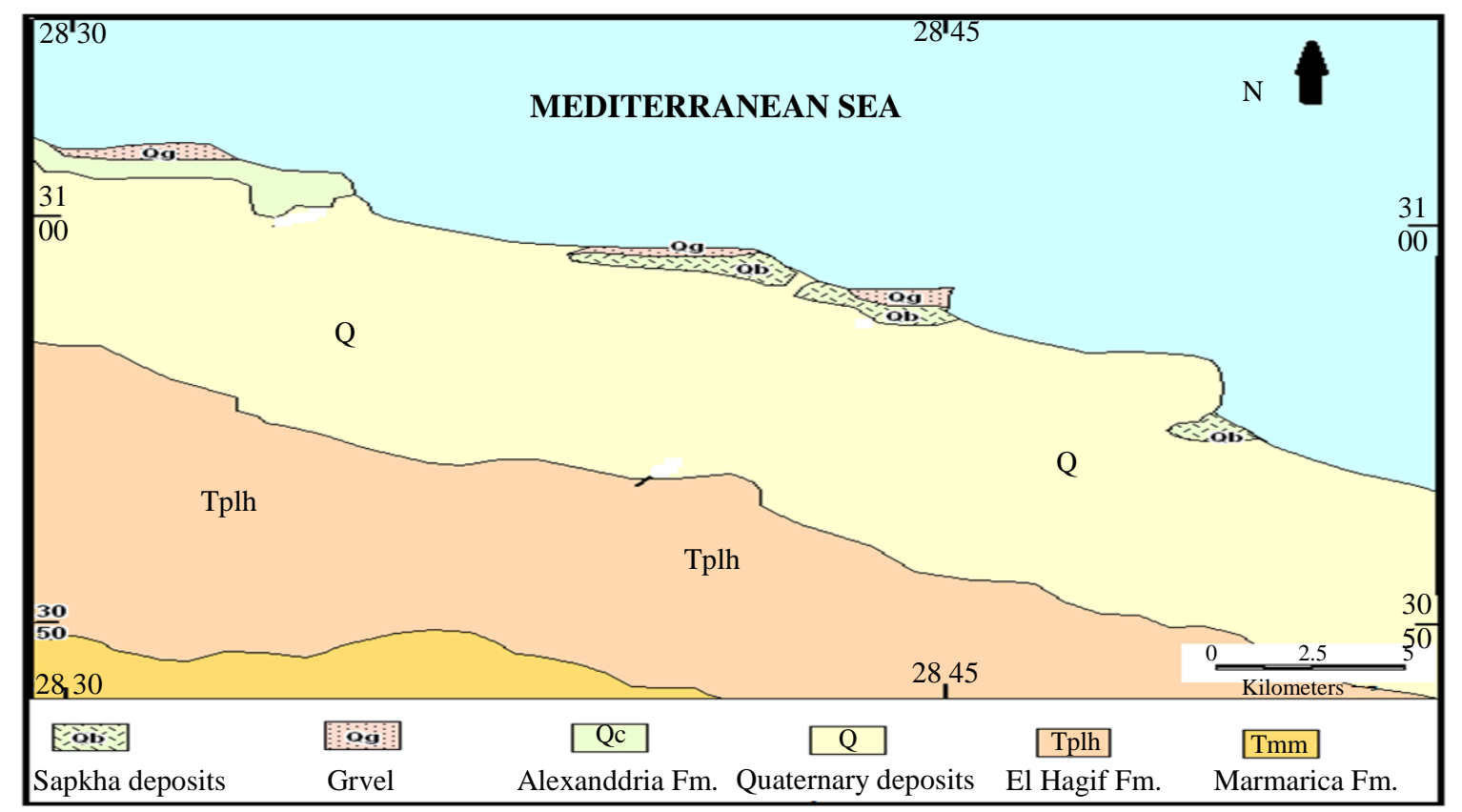

Fig. 2: General geology of the study area

\section{El Hagif Formation}

This formation was formed in shallow marine environmental conditions. It is snow white color and intercalated with marl and marly limestone layers of rosy color and extends toward the west to El Dabaa direction.

\section{Marmarica Formation}

This formation also was formed in shallow environment in the middle tertiary and composed of fossil ferrous limestone intercalated with silt, clay and marl.

\section{Topographic Investigation}

Topographic maps of northern coast have been carried out to cover all area of reservoirs. Topographic maps and cultural features are often helpful to the designer. The maps show that, maximum elevation of the surrounding high lands reaches about $22 \mathrm{~m}$ (a.s.l) while minimum elevation is about $0 \mathrm{~m}$ (a.s.l) at the outlet where the most infrastructures of the northern coast main road are found, this indicates how these infrastructures are suffered from sea water. The area is characterized by an irregular landscape which consists mostly of hard limestone rocks forming very rugged peaks. These rocks are highly fractured that store much of the precipitation through the structurally controlled drainage network with various widths dissect the mountainous terrain. Floor of the wadis in the study area is covered by a considerable thickness of Quaternary deposits of ranges between $3 \mathrm{~m}$ and $12 \mathrm{~m}$. The Quaternary deposits consist of different types of sediments (sand-gravel-silt and rock fragments).

\section{Geophysical Investigation}

Geophysical methods are used to determine indirectly the extent and nature of geologic materials beneath the surface. Thickness of unconsolidated surficial materials, depth to water table, location of subsurface faults and depth of the basement rocks can be predicted via geophysical investigation. In some instances, thickness and extent of subsurface bodies, such as gravel deposits or clay layers, can be evaluated.

The main objective of this study is to conduct geoelectric resistivity survey in order to investigate the lithological succession beneath the surface cover of the study area and to determine the properties of each layer. Also, it aims to locate areas having high potentialities of groundwater.

No Geophysical surveys have been done before in the study area (Yahia et al., 2017). Geophysical measurements are required to define geological conditions in the different water bearing formations in the area. Using geological and geophysical studies, aquifer's geometry, boundary conditions and quantity/quality of ground water, may be defined. In this research it has carried out a geophysical survey by measuring a considerable number of Vertical Electrical Sounding (VES) at the study area. These VES, $\mathrm{s}$ was arranged in profiles along the area as shown in Fig. 3. Electrode spacing was chosen to penetrate a depth of about $(60-100 \mathrm{~m})$ in order to show the nature of the subsurface rock unit and its properties. 


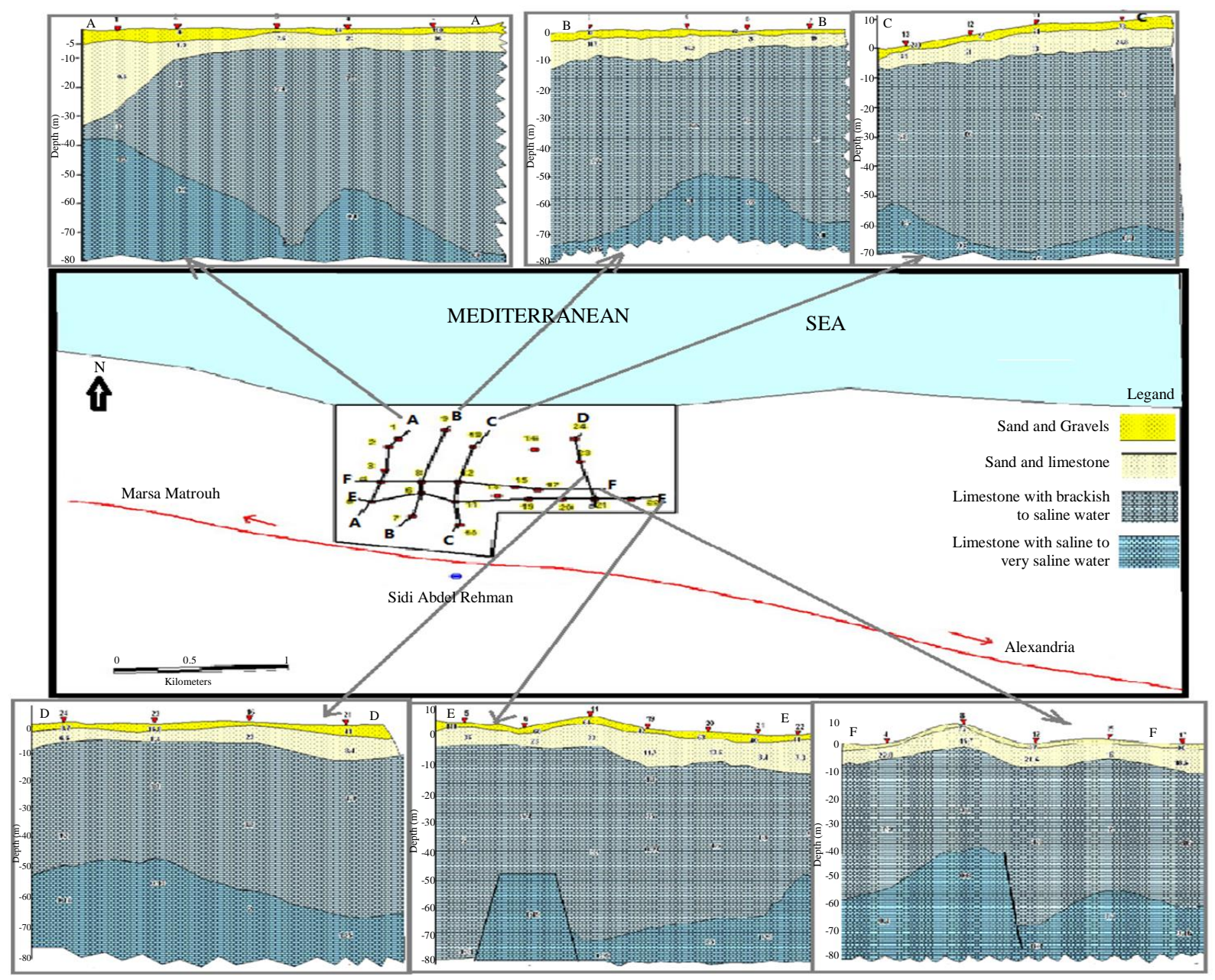

Fig. 3: Location of VES and profiles

\section{Methodology}

The tetrameter Mc. Ohm (OYO) is used for conducting geo-electric field survey. This instrument permits natural or induced signals to be measured at extremely low levels, with excellent penetration and low power consumption. Moreover, it can be used in a wide variety of applications where effective signal/noise discrimination is needed.

Many electrode configurations can be applied in the resistivity measurements. The choice of electrode configuration depends on the depth of investigation, type of information needed and the application of the measurements. In the present work, Schlumberger (1920-1940) (Bowker, 1995) configuration is used in measuring the Vertical Electrical Sounding (VES) to get the electric resistivity distribution of subsurface formations. All measurements were carried out with increasing $\mathrm{AB}$ (current electrode spacing) with the rate of about 6 measurements per logarithmic decade. Every measurement was recorded twice, changing the supply voltage. According to these results the mean relative error of measurements is calculated to be equal to $2.4 \mathrm{ohm}$ 's which is regarded satisfactory.

\section{Interpretation of Resistivity Data}

The measured apparent resistivity was subjected to some field corrections and plotted on a logarithmic paper to give the field curve. The field measurements were interpreted qualitatively and quantitatively.

The main purpose of the qualitative interpretation is to determine the number of the geo-electrical layers in terms of thickness (or depth) and relative resistivity. This is done by plotting the field measured apparent resistivity against half-electrode spacing $(\mathrm{AB} / 2)$ and by the construction of field curves which guide through the quantitative interpretation.

The quantitative interpretation is an analytical technique that can be performed on the vertical electrical sounding using computerized software constructed for such purpose. In the present study, the software of "RESIX-P" (1996) (RESIX-P and Interpex, 1993) was used for non-automatic iterative interpretation. This 
program compares the field data with the data calculated from initially assumed layer models. The initial model was constructed based on the lithological succession from the available data of the area (WRRI, MWRI, 2013).

\section{Results and Discussion}

The results of the quantitative and quantitative interpretation, in the form of layer thickness and true resistivity, are illustrated in geo-electrical cross-sections that investigate lateral and vertical changes of the formation properties.

Based on the available lithological in formations and the results of resistivity data, six vertical electric cross section were constructed. Detailed inspection of their sections indicated four geo-electric units reflect different lithological layers. These units from top to bottom as follows

\section{First Unit}

The top surface unit of resistivity range from 4 to 240 ohms comprises thickness less than five meters. This unit is interpreted as thin layer composed of wadi deposits (sand and gravels). In some parts where the minimum resistivity values, this layer contain groundwater in its lower part. The salinity of this water depends on elevation and the distance to coast where it is directly connected to the sea.

\section{Second Unit}

This unit underlies the surface unit and comprises a resistivity ranges from 1.3 to $23 \mathrm{ohm}$ 's and thickness varies from $5 \mathrm{~m}$ to $27 \mathrm{~m}$. This unit reflects a layer composed of sand in some parts where the lower resistivity and fractured limestone where the higher resistivity values. It is noticed that in the resistivity values increase toward the south (away from the sea) which mean that this layer may collect some fresh water during rainy seasons. Accordingly, the high topographic soundings sites may be promising for brackish water. The maximum thickness of this layer was found beneath VES No. 1 and the minimum thickness beneath VES 23. The higher resistivity values at VES's 8 and 11 indicate the probabilities of brackish water.

\section{Third Unit}

This unit comprises low resistivity values and great thickness. It was interpreted as limestone. The lower resistivity values reflect the availability of groundwater in this layer but the values indicate that this water is brackish to saline.

\section{Fourth Unit}

It is the base of the investigated interval which varies in depth from 50 to $100 \mathrm{~m}$ and of undefined thickness. This unit reflects a thick layer of limestone saturated with saline water in its lower section.

\section{Hydrology}

A hydrological study has been carried out for the study area. A topographic map of scale 1: 50000 is used to create the Digital Elevation Model (DEM) for study basin using Geographical Information System (GIS) (NRC, 2015). The DEM and the resulted drainage network of the area are shown in Fig. 4.

Daily rainfall data is collected in and around the study area. It is collected from the General Meteorological Authority (GMA) and Water Resources Research Institute WRRI stations. The closest rainfall station is Marsa Matrouh station. All the rainfall data is used to analyze the rainfall values for different return periods up to 100-year.

The methodology for the hydrological study of this area is based on the use of a deterministic conceptual model that converts precipitation to runoff as implemented in HEC-1 model for the U.S. Army Corps of Engineers (1998). Accordingly, one of the recent hydrologic models called Watershed Modeling System (WMS) is used to compute the runoff hydrograph. This program is developed by Brigham young university (2005). Different hydrologic data are used to feed the program to get the basin hydrograph for different return periods up to 100-year. The result of the hydrologic analysis showed that all rainfall amounts are infiltrated to the soil and there is no runoff flood water to affect the study area. Consequently, it's concluded that the flood has no harm effect on any of the study area buildings.

\section{General Results and Discussion for Groundwater Potentiality Studies}

The area has a complex sedimentary condition where the surface layer varies from lose sands to calcareous deposits and sabkhas are dominant feature especially in the central part of the area. The water bearing section is thick and comprises all sedimentary units of the investigated interval below the sea level in most of the area. In the study area, there are two separate narrow sheet zones of fresh water potentiality as shown in Fig. 5. The fresh water is expected to be found as a thin film of low productivity depend on the seasonal recharge from rainfall.

This thin film occurs above sea level and controlled by elevation and rock type. It was found in wadi deposits of sand and gravel in the southwestern part and in fractured limestone in the southeastern part. Moreover, results indicated that the salinity of groundwater increases towards the north (to the Mediterranean Sea) as a result of sea water intrusion. Based on the geophysical and hydrogeological results, it is strongly recommended drilling three productive wells to a depth of $\pm 50 \mathrm{~m}$ at the location of VESes 5 and 7 to produce water from the coral reef limestone layer where its high fracture density and lower salinity. For future sustainable development plans, it is also possible to drill any number of productive wells in the southern part of the area to avoid the higher degree of sea water intrusion. In this case, the distance between wells must be not less than $120 \mathrm{~m}$. Finally, its 
recommended to operate these wells in suitable discharge (pumping test) to avoid higher sea ware intrusion. Table 1
Shows the description of the lithological description of wells A, B and C, Also schematic diagram for each well.

Table 1: Shows the description of the lithological description of wells A, B and C, Also schematic diagram for each well

Litho logic description of the well "A"

This well is drilled between the site of sounding no 5 and sounding no. 7. The coordinates of this well is defined in the main report. Here are the details of this well: -

- Well code: A

-total drilling depth: $57 \mathrm{~m}$

-Cased well depth: $50 \mathrm{~m}$

-Sand trap: from 48-50 m depth

-Screen : from 48-24 m depth

\section{Litho logical succession}

Wadi deposits

(sand \&gravels) 0-2 m

Loose sand and silt $\quad 2-6$

Fine sand and some clay 6-10

Fractured limestone 10-18

Dolomitic limestone 18-21

Intercalation of sand and limestone 21-36

Dolomitic limestone 36-39

Fractured limestone 39-57

During drilling, water samples were taken each 1 meter and $\mathrm{Ph} \& \mathrm{EC}$ were measured. As a result of increasing salinity from the depth of $49 \mathrm{~m}$ and downward, the well was cased to $50 \mathrm{~m}$ and the sand trap was installed from depth of 48 to avoid the higher salinity. Fig. a shows the final design of this well.

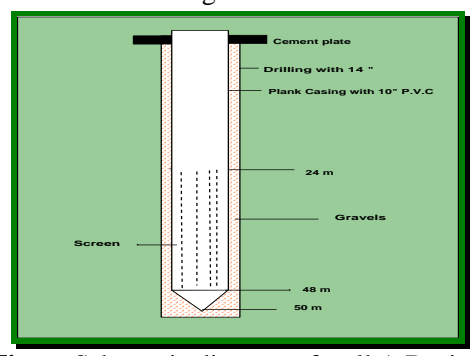

Fig. a: Schematic diagram of well A Design

Litho logic description of the well "B"

This well is drilled at the site location of sounding

no. 7. The coordinates of this well is defined in the main report. Here are the details of this well: -

- Well code: B

-Total drilling depth: $51 \mathrm{~m}$

-Cased well depth: $48 \mathrm{~m}$

-Sand trap: from 48-46 m depth

-Screen: from 46-22 m depth

\section{Lithological succession}

Wadi deposits

(sand \&gravels) $\quad 0-2 \mathrm{~m}$

Loose sand and silt 2-6

Fine sand and some clay 6-8

Hard lime stone $\quad 8-10$

Fractured limestone 10-16

Dolomitic limestone 16-18

Sandstone with some shale $18-20$

Intercalation of sand and limestone $\quad 20-33$

Dolomitic limestone 33-36

Fractured limestone 36-51

During drilling, water samples were taken each 1 meter and $\mathrm{Ph} \& \mathrm{EC}$ were measured. As a result of increasing salinity from the depth of $47 \mathrm{~m}$ and downward, the well was cased to $48 \mathrm{~m}$ and the sand trap was installed from depth of 46 to avoid the higher salinity. Fig. b. shows the final design of this well.

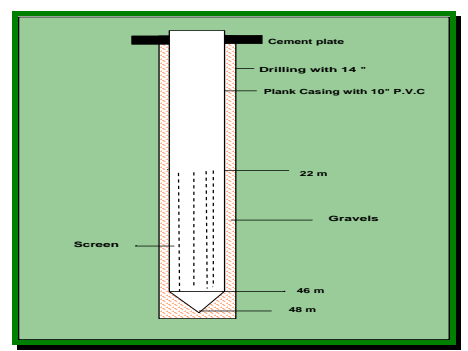

Fig. b: Schematic diagram of well B Design

Litho logic description of the well "C"

This well is drilled at the site location of sounding no. 5. The coordinates of this well is defined in the main report. Here are the details of this well: -

- Well code C

-total drilling depth $47 \mathrm{~m}$

-Cased well depth $42 \mathrm{~m}$

-Sand trap from 42-40 m depth

-Screen from 40-16 $\mathrm{m}$ depth

\section{Litho logical succession}

Wadi deposits

(sand \&gravels) $\quad 0-1 \mathrm{~m}$

Loose sand and silt $1-4$

Fine sand and some clay 4-7

Reefal cracked lime stone $7-11$

Fractured limestone 11-18

Dolomitic limestone $\quad 18-20$

Sandstone with some shale 20-23

Intercalation of sand and limestone 23-27

Dolomitic limestone 27-36

Fractured limestone $\quad 36-47$

During drilling, water samples were taken each 1 meter and $\mathrm{Ph} \& \mathrm{EC}$ were measured. As a result of increasing salinity from the depth of $41 \mathrm{~m}$ and downward, the well was cased to $42 \mathrm{~m}$ and the sand trap was installed from depth of 42 to avoid the higher salinity. Fig. c. shows the final design of this well.

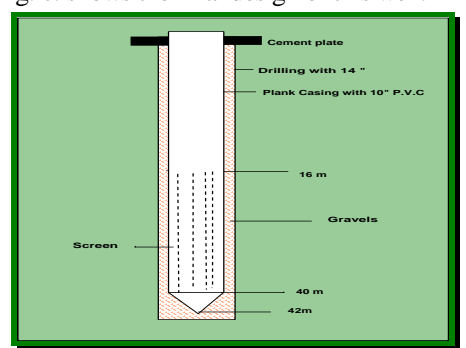

Fig. c: Schematic diagram of well C Design

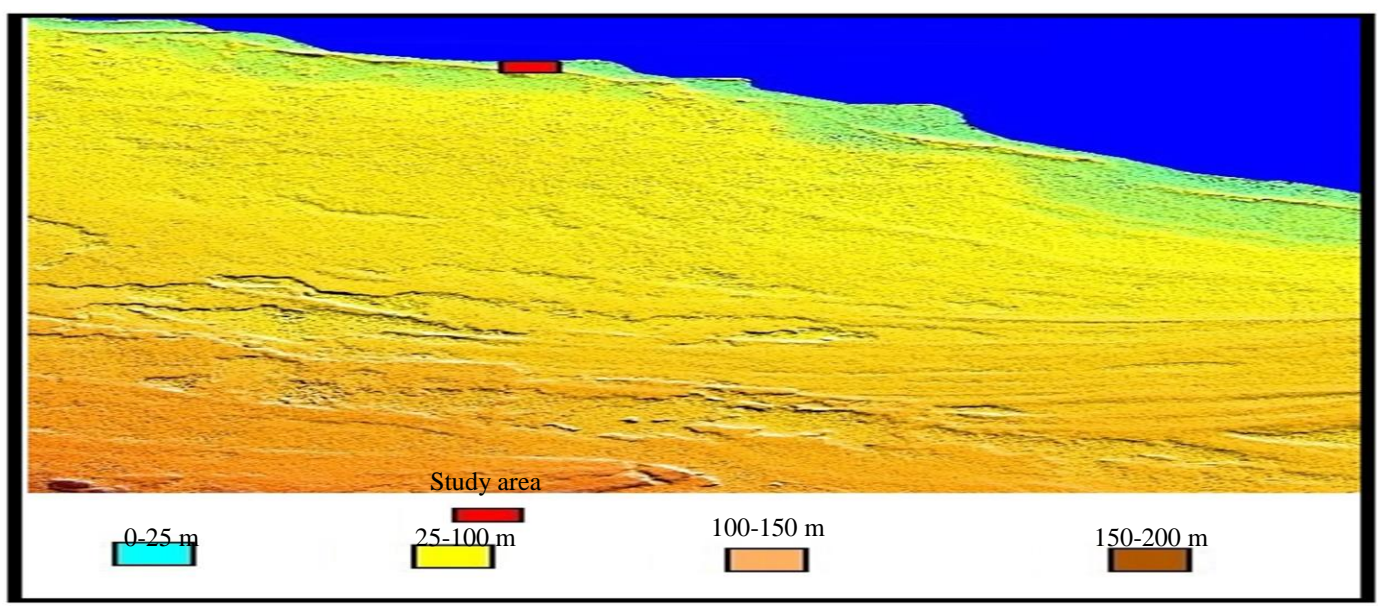

Fig. 4: The DEM and the resulted drainage network of the area 


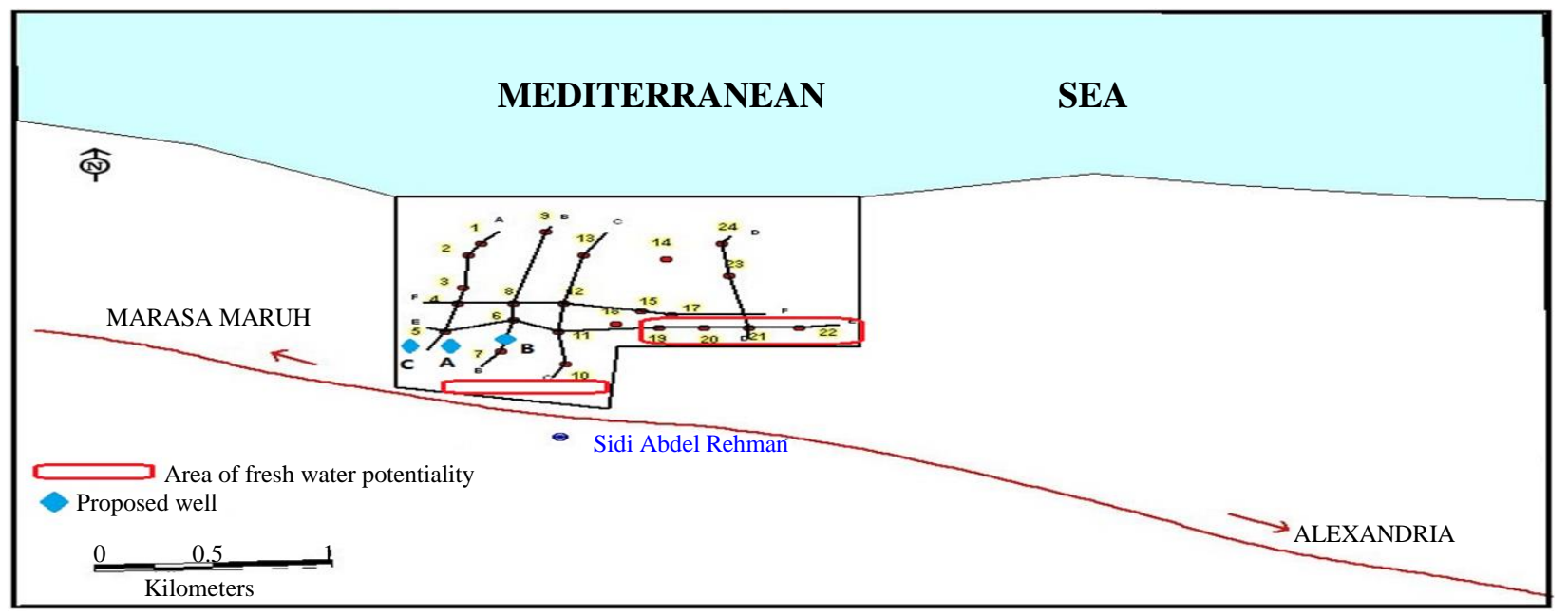

Fig. 5: Location of proposed wells

\section{Hydro Chemical Study}

Five samples were collected from 5 wells around the study area as shown in Fig. 6.

The well data inventory also collected such: Total depth, water table, elevation and Total Dissolved Solids TDS as shown in Table 2.

The location of the wells near or along the coast of the Mediterranean Sea reflects the effect of the sea water especially in well No.2, this wells has salinity $37888 \mathrm{ppm}$ which is considered the same of the salinity of the Mediterranean Sea. The depth of these wells reaches $33 \mathrm{~m}$ and the elevation is zero, this means that wells penetrates a sedimentary layer completely saturated by sea water.

The well no. 4 has a salinity 1516 ppm, compared with depth and elevation, the depth is $22 \mathrm{~m}$ also elevation $14 \mathrm{~m}$ and the water table is $15 \mathrm{~m}$. this means that the water bearing formation is recharged from the rainfall. this well locates south inland the other three wells, 1,3 and 5 have a salinity range between 2931 and $5792 \mathrm{ppm}$.

From the complete chemical analyses for the 5 wells, the main dominant major cations are $\mathrm{Na}, \mathrm{Mg}, \mathrm{Ca}$ and the main dominant anion are the $\mathrm{So}_{4}$ and $\mathrm{HCO}_{3}$. The trace elements include $\mathrm{Al}, \mathrm{Fe}, \mathrm{Mn}$ and $\mathrm{Ni}$. The main salt is the $\mathrm{Nacl}, \mathrm{Mgcl}, \mathrm{MgSO}_{4}$ and $\mathrm{CaCo}_{3}$.

Depending on the World Health Organization (WHO) and Egyptian organization for Standardization and quality in water for human drinking. Table 3 shows the average water quality for 5 wells samples. It is clear that for TDS, (100\%) of groundwater samples is unsuitable for human drinking (>1000 mg/l), like sodium and chloride samples. While $80 \%$ of the samples are within limits for calcium, magnesium, manganese and iron. (EPA, 1986; WHO, 2003; 2006).

\section{Shore Line Mathematical Modelling and Numerical Simulation of the Study Area}

The total length of the study area coastline is about $1200 \mathrm{~m}$. An intake and an outlet structures are determined to be implemented. It is conducting a numerical simulation model to the coastline of the study area in order to inspect the effects of implementing the structures. For that reason, a topographical and a bathymetrical survey were carried to the area in order to simulate the area numerically.

The topographical survey covered an area of $200 \mathrm{~m}$ from the low water Level landwards up to $+3.0 \mathrm{~m}$ above the M.S.L. On the other hand, the bathymetrical survey covered an area of $8 \mathrm{Km}^{2}$, with a distance of $4.0 \mathrm{~km}$ alongshore. The survey extended $2.0 \mathrm{~km}$ offshore. It is to be noted that the topographic survey was overlapped with the bathymetric survey by at least 50 meters to allow an integrated mapping of the results.

As for the numerical model, it was used to simulate a total area of $4 \times 2 \mathrm{~km}^{2}(4 \mathrm{~km}$ along the shore line and $2 \mathrm{~km}$ offshore). The shore study consists of three parts. First it is displaying the topographical and bathymetrical surveys while the second is including a numerical modeling process. Finally, extracted conclusions and some recommendations to be followed to avoid the occurrence of any undesirable condition (HRI, MWRI, 2012; 2013).

\section{Topographic Survey}

The topographic survey carried out to cover $200 \mathrm{~m}$ from low water Level up to $+3.0 \mathrm{~m}$ above the mean sea water level whichever is closer and the topographic survey was overlapped with the bathymetric survey by at least $50 \mathrm{~m}$ to allow an integrated mapping of the survey results. 


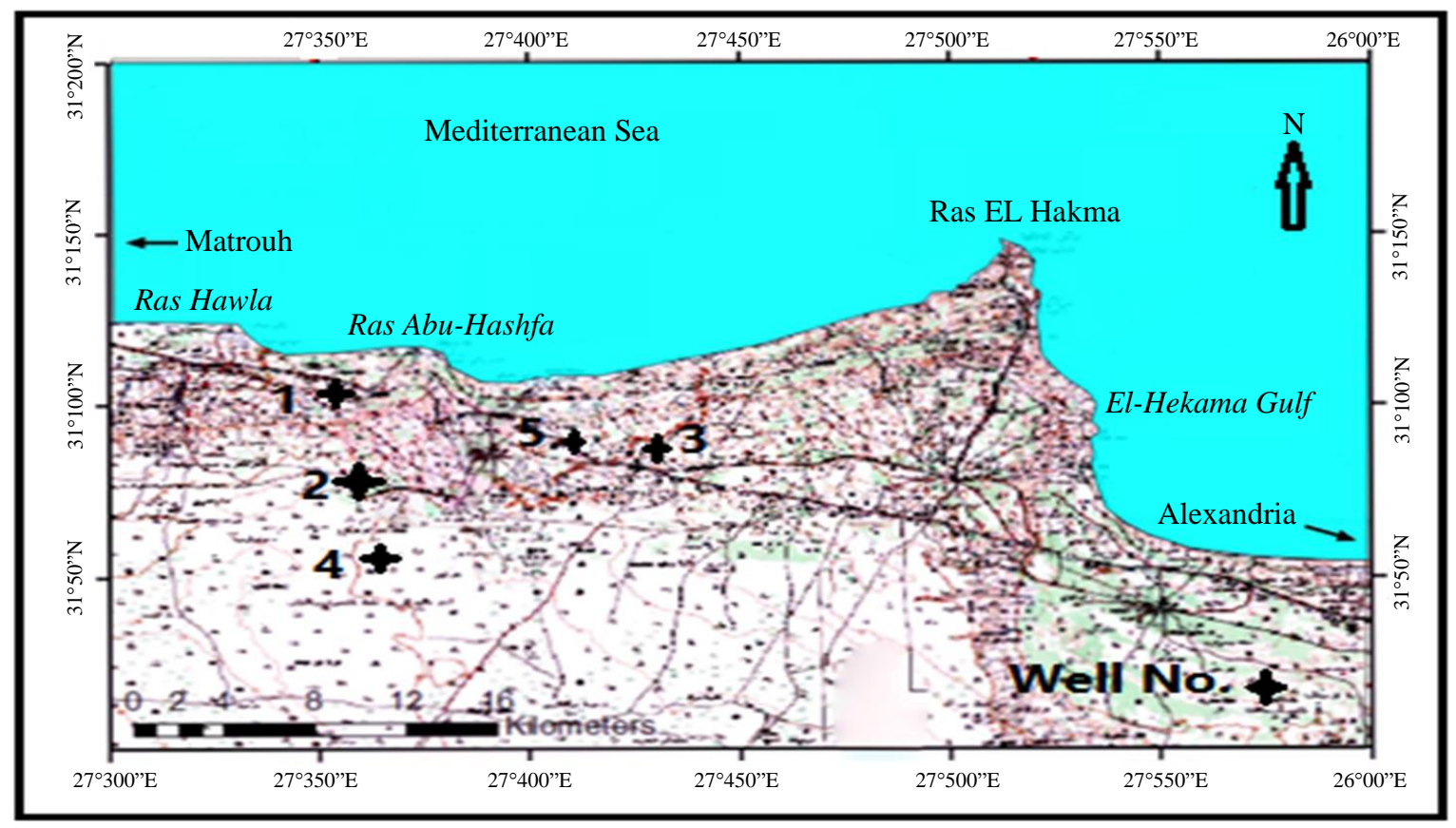

Fig. 6: Location of the sampled water wells in the surrounding areas

Table 2: Well inventory data of the collected samples

\begin{tabular}{lllll}
\hline No. & Depth $(\mathrm{m})$ & Water Table $(\mathrm{m})$ & TDS $(\mathrm{mg} / \mathrm{L})$ & Elev-m.asl $(\mathrm{m})$ \\
\hline 1 & 6 & 6 & 6892 & 6 \\
2 & 33 & 1 & 37888 & 0 \\
3 & 27 & 17 & 2931 & 16 \\
4 & 22 & 15 & 1516 & 14 \\
5 & 20 & 12 & 5792 & - \\
\hline
\end{tabular}

Table 3: Water quality guidelines for human drinking for the investigated 5 wells in the study area (WHO, 2008)

\begin{tabular}{lllllll}
\hline Parameter & WHO & Egyptian standard & Range & Mean & $\begin{array}{l}\text { No. of samples within } \\
\text { the permissible limit }\end{array}$ \\
\hline TDS mg/L & 1000 & 1000 & $1516-37888$ & 2652 & 0 & 0 \\
$\mathrm{pH}$ & $6.5-8.5$ & $6.5-9.5$ & $7.05-8.2$ & 7.6 & 5 & 100 \\
Sodium mg/L & 200 & 200 & $340-12250$ & 6295 & 0 & 0 \\
Calcium mg/L & 350 & - & $108-540$ & 324 & 4 & 80 \\
Magnesium mg/L & 150 & - & $25-226$ & 125.5 & 4 & 80 \\
Chloride mg/L & 250 & 250 & $514-18500$ & 9507 & 0 & 0 \\
Sulfate mg/L & 250 & 400 & $215-2450$ & 1332 & 2 & 80 \\
Manganese mg/L & 0.05 & 0.1 & $0.039-0.161$ & 0.1 & 4 & 80 \\
Iron mg/L & 0.3 & 0.3 & $0.018-0.351$ & 0.0266 & 4 & \\
\hline
\end{tabular}

Table 4: Presents the coordination for the bench marks

\begin{tabular}{lll}
\hline Point & East & North \\
\hline $\mathrm{m} 1$ & 660216.12 & 3431092.85 \\
$\mathrm{~m} 2$ & 660441.87 & 3431035.20 \\
$\mathrm{~m} 3$ & 660864.53 & 3431081.30 \\
\hline
\end{tabular}

\section{Bathymetric Survey}

The bathymetric survey covered an area of $8 \mathrm{Km}^{2}$, with a distance of $4.0 \mathrm{~km}$ alongshore. This distance covers $1.4 \mathrm{~km}$ east of the study area and $1.5 \mathrm{~km}$ west and extend to $2.0 \mathrm{~km}$ off-shore (ECIDSC, UNDP,
2011; GCF, 2017). The survey was carried out in beach profiles (cross-sections), 43 beach profiles were measured with 100 meters' distance apart. The bathymetry of each beach profile was carried out by two methods:

a. Manually using staff gauge and the total station, for the shallow area

b. Sounding using Echo sounder (DSF-600 Digital Survey Fathometer) installed in a rubber boat started after the shallow area to more than $2 \mathrm{~m}$ water depths 


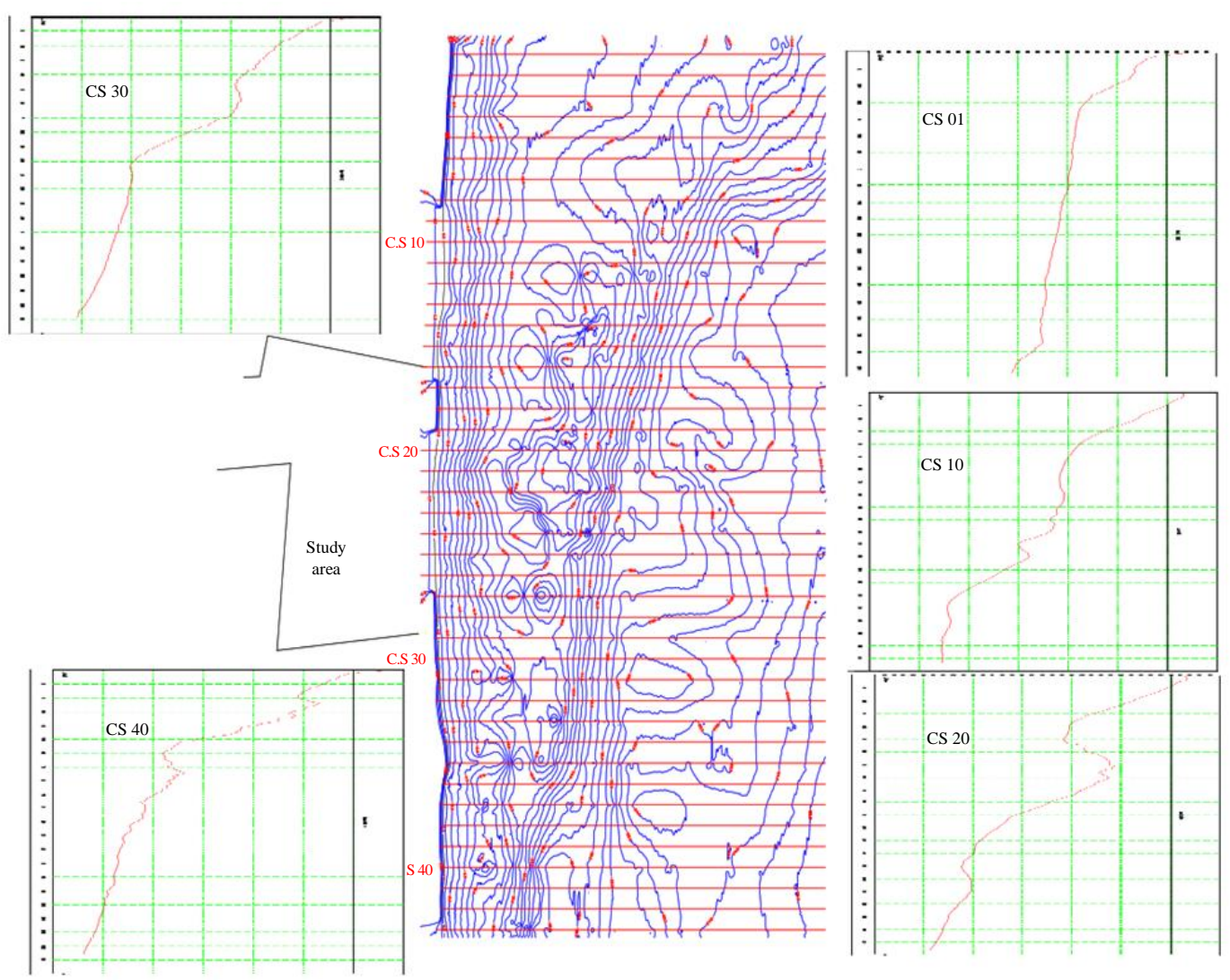

Fig. 7: General layout for the surveyed area and the locations of the measured profiles

The measured data is used to draw the contour map for the surveyed area using SURFUR software. All shoreline facilities were identified in the contour maps. Bathymetric maps with UTM projection coordinates and contour step of $1.0 \mathrm{~m}$ were carried out. The study area boundaries were measured and it is presented in the contour map. Three bench marks were established in the site and its coordinates were determined as shown in Table 4. All bathymetric information is finalized by the AUTOCAD software (Autodesk, 2012). Figure 7, shows a general layout for the surveyed area and the locations of the measured profiles.

From the measurements, it is clear that the beach is West-East oriented, with no undulations. This means that the beach is natively stable. Based on the level of confidence of the data obtained from the topographical and bathymetrical surveys, they were input to the numerical model.

\section{Numerical Modeling Simulating for the Future Shoreline Shape using Genesis Model}

In order to simulate the future shoreline shape, a numerical model, GENESIS was used. It will first introduce the model used in the simulation, theory, input and output files. Second displays the executed numerical simulations (Hans Hanson and Kraus, 1989). The executed numerical simulation will encompass the future shoreline computations with and without implementing the structures. This will be achieved in order to evaluate the effect of the structure on the shoreline. Finally, some comments are given to evaluate the induced impacts on the shoreline. Also, the comments will introduce some recommendations to be followed in the future to avoid the occurrence of any undesirable conditions.

\section{Model Genesis}

Model Genesis is a worldwide accepted model that can be applied in the scoping and designing modes. In the scoping mode, the shoreline can be simulated to have an appreciation for the shoreline changes. In the design mode, several alternatives can be simulated and their impact can be studied and compared to choose the most reliable of them.

\section{Theory of Model Genesis}

Model GENESIS is based on the one-line theory, where the shoreline is represented by a line. Theoretically, the model is based on the continuity equation to a wedge with a chosen width. This wedge should be balanced in order to obtain the shoreline changes.

Model GENESIS is based on the finite difference, where the shoreline is represented by offsets projected on a baseline at equal distances from each other. The 
model considers the breaking according to the slope of the foreshore. This is executed via breaking equations that are internally solved in the model to obtain the breaking conditions. These breaking conditions dominate the calculation zone.

\section{Input Files to Model GENSIS}

In order to operate the model, 4 input files are needed. These are:

- The instruction file: This file carries the instruction to be dictated to the model to execute the simulation process. For example, the total simulation period, the time step in order to execute the calculations on small intervals to make the results more accurate. This file also holds the specifications of any added structure. In our case here, the structures are the intake and outlet

- The wave data file: This file holds the wave conditions on daily basis or as chosen in the time step specified in the instruction file

- The initial shoreline data file: This file carries the initial position of the shoreline as coordinates related to a chosen base line

- The measured shoreline data file: This file holds the measured historical shoreline positions. This is used for comparison purposes during the calibration process. In our case here, no previous measurements were available

\section{Output Files to Model GENSIS}

The model supplies the operator with 2 output files. These are.

\section{The Output File}

This file carries the details of the calculations and the breaking conditions and the sediment transport quantities.

\section{The Final Shoreline Data File}

This file holds the final shoreline data at the end of the simulation period that was specified in the instruction file.

\section{Numerical Simulations}

The model was applied in 2 modes [ scoping mode design mode].

First: Scoping mode where the shoreline was simulated to have an appreciation for the shoreline changes before adding any structures. Second: design mode for different structures were simulated in order to choose the suitable case for beach condition.

\section{Preparing the Input Files}

The input files were prepared using the field data. The following steps were followed:
- The shoreline was projected to a baseline and the offsets were measured and input in the shoreline data file

- The specifications and orientation of the structures were precisely described in the instruction file

- The wave data were introduced into the wave data file

During the preparation, these things were considered: [The wedge width was chosen to be $100 \mathrm{~m}$ in order to consider the undulation in the shoreline, the time interval was taken $24 \mathrm{~h}$, which means the shoreline will be predicted every $24 \mathrm{~h}$. This is considered a very precise computation and the simulation period was chosen to be 5 years which is considered to be reasonable. This is because the shoreline is expected to have slight changes after these 5 years].

\section{Future Shoreline before Adding the Structure}

The initial shoreline, Fig. 8, was simulated before implementing the port or any other structure. The model was run and the results were obtained and plotted, Fig. 9.

From the results, it was clear that the shoreline would experience almost no changes as it is considered to be a stable shoreline segment, Fig. 10.

\section{Future Shoreline after Adding the Structure}

The shoreline was simulated using 20 different orientations to the intake and outlet structures. The model was run and the results were obtained and plotted. Comparing the results, it is clear that alternative 6 was the most suitable orientation to the beach condition. This case is shown on Fig. 11. From the results, it was clear that the shoreline would slightly change due to the presence of the structure.

The shoreline slightly accretes at the up-drift of the structures with a rate of $2 \mathrm{~m} / \mathrm{yr}$, the shoreline slightly erodes at the down-drift of the structures with a rate of 2 $\mathrm{m} / \mathrm{yr}$ and the shoreline is naturally stable as it is a smooth East-West shoreline with no undulations.

The amount of sediment transport is trivial Fig. 12. That is the reason that the alignment of the structure will not induce negative impacts on the shoreline. But slight effects are evident to occur.

\section{Comments and Analysis of the Numerical Modeling}

Based on the above, the following are the recommendations that are to be followed in the future to avoid the occurrence of any undesirable conditions: [Bathymetrical surveys should be executed periodically in order to assist the results of the model- If any unexpected event occurred and severe changes took place, then by pass should be undergone, to transport the sediment from the up-drift side to the down-drift of the structures so as not to induce an unfavorable condition to the down-drift - As for swimmers, it is advised to mark the location of the structures so that the people accessing the beach might not swim near the structures]. 


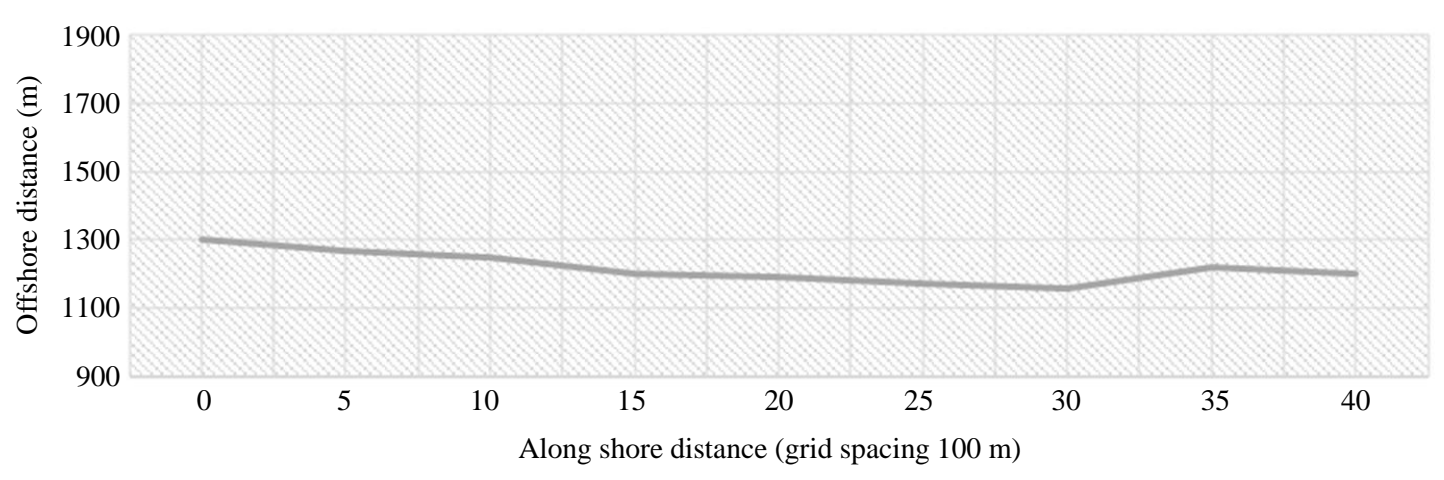

Fig. 8: Initial shore line



Fig. 9: Final Shore Line Before Adding Structures

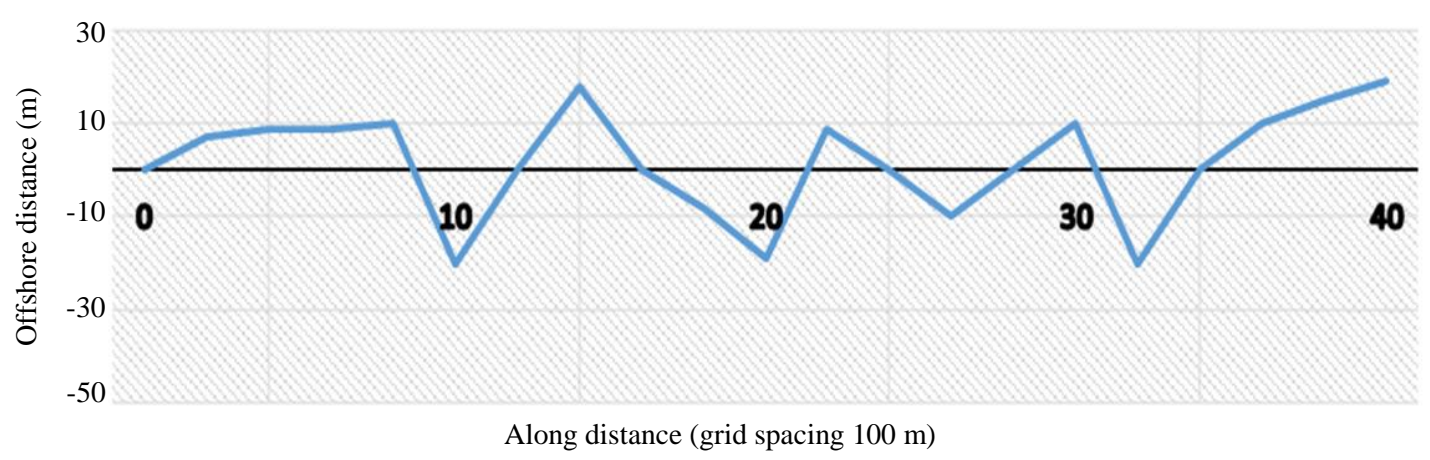

Fig. 10: Shore line change

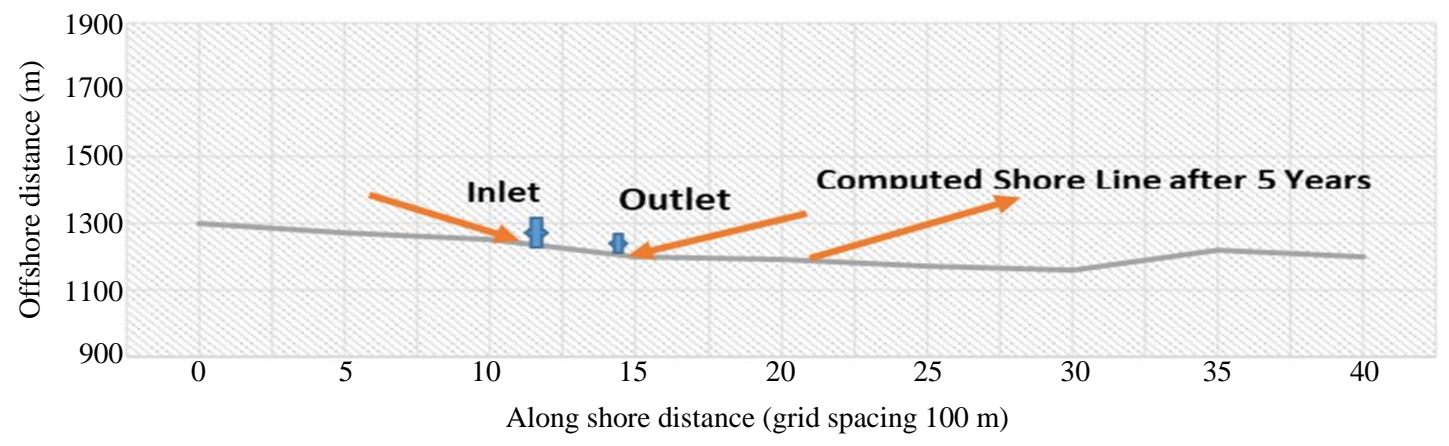

Fig. 11: Final Shore line after adding Structure 


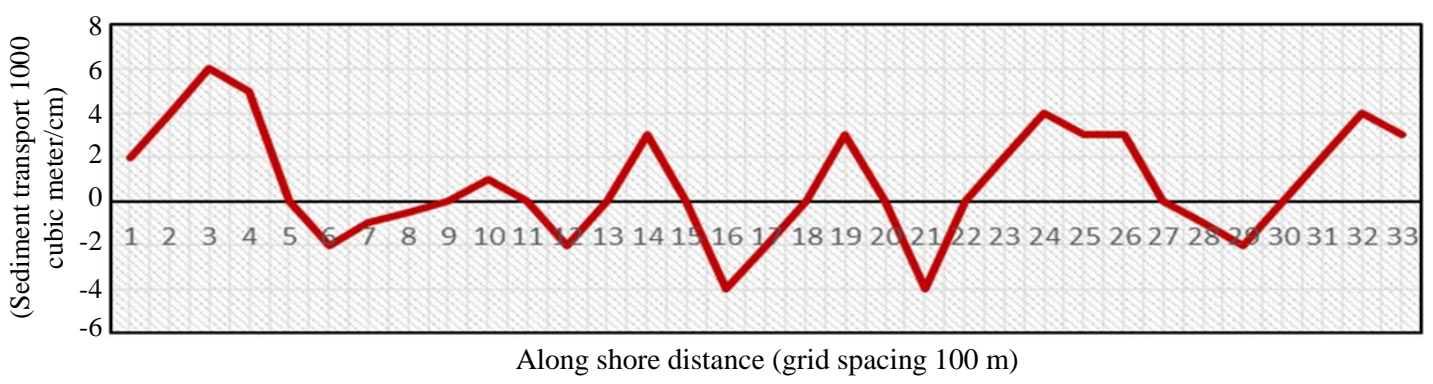

Fig. 12: Sediment transport

\section{Conclusion}

The area has a complex sedimentary condition where the surface layer varies from lose sands to calcareous deposits and sabkhas are dominant feature especially in the central part of the area. The water bearing section is thick and comprises all sedimentary units of the investigated interval below the sea level in most of the area.

In the study area, there are two separate narrow sheet zones of fresh water potentiality where the fresh water is expected to be found as a thin film of low productivity depend on the seasonal recharge from rainfall. This thin film occurs above sea level and controlled by elevation and rock type. It was found in wadi deposits of sand and gravel in the southwestern part and in fractured limestone in the southeastern part.

Results indicated that the salinity of groundwater increases towards the north (to the Mediterranean Sea) as a result of sea water intrusion. Depending on the World Health Organization (WHO) and Egyptian organization for Standardization and quality in water for human drinking It is clear that for TDS, a major part of samples $(100 \%)$ of total groundwater samples is unsuitable for human drinking (>1000 mg/l), like sodium and chloride samples. While $80 \%$ of the samples are within limits for calcium, magnesium, manganese and iron.

The shoreline slightly accretes at the up-drift of the structures with a rate of $2 \mathrm{~m} / \mathrm{yr}$. The shoreline slightly erodes at the down-drift of the structures with a rate of 2 $\mathrm{m} / \mathrm{yr}$. The shoreline is naturally stable as it is a smooth East-West shoreline with no undulations. Based on the modeling results, it was noticed that the shoreline is naturally stable as it is a smooth East-West shoreline with no undulations and the amount of sediment transport is trivial. That is the reason that the alignment of the structure will not induce negative impacts on the shoreline. But slight effects are evident to occur.

For future sustainable development plans, it is also possible to drill any number of productive wells in the southern part of the area to avoid the higher degree of sea water intrusion. In this case, the distance between wells must be not less than $120 \mathrm{~m}$. From the field reconnaissance, clear was that the beach is West-East oriented, with no undulations. This means that the beach is natively stable. Bathymetrical surveys should be executed periodically in order to assist the results of the model. If any unexpected event occurred and severe changes took place, then by pass should be undergone, to transport the sediment from the up-drift side to the down-drift of the structures so as not to induce an unfavorable condition to the down-drift.

\section{Acknowledgement}

The corresponding author expresses her gratitude to Prof. Tarik Tawfic, former director of the Central Laboratory for Environmental Quality Monitoring, Ministry of Water Resources and Irrigation, Cairo, who moderated this paper and in that line improved the manuscript significantly. She also is immensely grateful to professors in National Water Research Center, Cairo for their comments on an earlier version of the manuscript, although any errors are her-own and should not tarnish the reputations of these esteemed experts. The corresponding author states that there is no conflict of interest. This research did not receive any specific grant from funding agencies in the public, commercial, or not-for-profit sectors.

\section{Conflict of Interest}

The Author declare that no conflict of interest regarding the publication of this paper.

\section{Ethics}

The author declares that there are no ethical issues that could arise after the publication of this study.

\section{References}

Abd-Alrahman, A.A.E. and S.E.A. Shanab, 2012. Geochemistry of quaternary aquifer groundwater in burg el Arab area and its suitability for irrigation. J. Am. Sci. 
Autodesk, 2012. AutoCAD 2013: Command reference guide.

Aya, A.S.G., M.E.A. Ali, H.A. Shawky and M.S.A. Abdel-Mottaleb, 2017. Hydrochemistry and evaluation of groundwater in Sidi Barrani, Egypt, determination of the best sites for desalination plants. Curr. Sci. Int., 06: 458-470.

CAPMS, 2017. Statistical Yearbook-2017 CAPMAS Release No. 108. Central Agency for Public Mobilization and Statistics

ECIDSC, UNDP, 2011. Egypt's national strategy for adaptation to climate change and disaster risk reduction. Egypt's Cabinet Information and Decision Support Centre.

EPA, 1986. Water quality standards for coastal waters marine outfalls. Environmental protection agency.

GCF, 2017. Enhancing climate change adaptation in the north coast and Nile delta regions in Egypt: Environmental and social management framework. Green Climate Fund.

Bowker, G.C., 1995. Information management and industrial geophysics at Schlumberger, 1920-1940. The President and Fellows of Harvard College.

Hans Hanson, N. and N.C. Kraus, 1989. Genesis: Generalized Model for Simulating Shoreline Change. Report 1. Technical Reference.

HRI, MWRI, 2012. Field measurements at Hadyek ELAlamin Village. Hydraulic Research Institute

HRI, MWRI, 2013. Numerical simulation to Hadyek ELAlamin Village. Hydraulic Research Institute

Hussein, H.M. and M.S.M. Barseem, 2018. Geophysical characterization of the coastal aquifer west el-qasr area, northwestern coast, Egypt. Egyptian Geophys. Society EGS J., 6: 145-158.

MOP, 2015. Ministry of planning. Egypt sustainable development strategy. Ministry of Planning 2030.www.mop.gov.eg/Vision1.pdf
Mustafa, A.E., H.H. Mahmoud, O. Stash, A. Shiekh and B. Parker, 2016. Geophysical and geochemical studies to delineate seawater intrusion in Bagoush area, Northwestern coast, Egypt. J. African Earth Sci., 121: 365-381. DOI: 10.1016/J.JAFREARSCI.2016.05.03

NRC, 2015. NRC Digital Elevation Model (DEM).

RESIX-P and Interpex, 1993. Interpretation software with user's manual. Interpex, Golden, CO. USA.

UN MDG, 2013. United nations development programme potential impacts of climate change on the Egyptian. Economy. United Nations Development Programme.

U.S. Army Corps of Engineers, 1998. HEC-1 flood hydrograph package- user's manual. US Army Corps of Engineers

WHO, 2003. WHO Guidelines for Safe Recreational Water Environments Volume 1: Coastal and Fresh Waters. 1st Edn., World Health Organization, ISBN10: 9241545801, pp: 219.

WHO, 2006. WHO Guidelines for safe recreational water environments creational water environments. 1st Edn., World Health Organization, ISBN-10: 9241546808, pp: 118.

WHO, 2008. WHO Guidelines for Drinking-Water Quality. 3rd Edn., World Health Organization, ISBN-10: 9241545356, pp: 142.

WRRI, MWRI, 2013. WRRI integrated study for groundwater potentiality in amwage resort project Km 136 Alex., Matrouh, Road.

Yahia, G., A.H. Al-Aassar, M. Amin, E. Shoukry and D. Assy, 2017. Hydro chemical characteristics and groundwater quality assessment for sustainable development at Ras El-Hekma Area-Northwestern Coast, Egypt. Curr. Sci. Int., 06: 589-622. 